\title{
Determination of copper(II) by flame atomic absorption spectrometry after its perconcentration by a highly selective and environmentally friendly dispersive liquid- liquid microextraction technique
}

\author{
Ghadamali Bagherian*, Mansour Arab Chamjangali, Hassan Shariati Evari and Motahare Ashrafi
}

\begin{abstract}
A new, simple, rapid, selective, and environmentally friendly method is proposed for the determination of $\mathrm{Cu}(\mathrm{II})$ ions based on the formation of the complex between these ions and salophen as the ligand followed by the dispersive liquid-liquid microextraction of the neutral hydrophobic complex formed in the organic phase and flame atomic absorption spectrophotometric detection. Various factors including the $\mathrm{pH}$ of the sample solution, concentration of salophen as the complexing reagent, type and volume of the extraction and disperser solvents, and extraction time affecting the extraction efficiency of $\mathrm{Cu}(\mathrm{II})$ ions and its subsequent analytical signal were

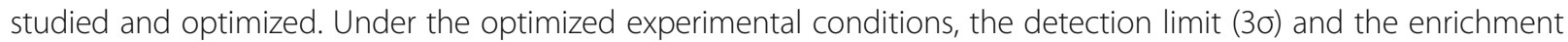
factor were obtained to be $0.60 \mathrm{\mu g} \mathrm{L}^{-1}$ and 49 , respectively, for $10.0 \mathrm{~mL}$ of the sample solution. The consumptive index was $0.20 \mathrm{~mL}$ and the calibration graph was linear in the range of 3.0-120 $\mathrm{g} \mathrm{L} \mathrm{L}^{-1}$. The relative standard deviations for six replicate measurements of $5.0,20.0$, and $50.0 \mu \mathrm{g} \mathrm{L}^{-1}$ of $\mathrm{Cu}(\mathrm{II})$ ions were $4.1 \%, 1.5 \%$, and $1.8 \%$, respectively. The proposed method was also successfully applied for the extraction and determination of $\mathrm{Cu}(\mathrm{II})$ ions in different water and food samples with satisfactory results.
\end{abstract}

Keywords: Dispersive liquid-liquid microextraction, $\mathrm{Cu}(I)$ ions, Atomic absorption spectrometry, Salophen

\section{Introduction}

Copper is a significant heavy metal, required for the human body (Behbahani et al. 2014; Özzeybek et al. 2017). However, it can cause serious problems at excess amounts (Behbahani et al. 2014). Copper enters the environment via different human and natural activities (Özzeybek et al. 2017; Yin et al. 2016). The utilization of copper-polluted water with a dosage of more than the legal level $(1.3 \mu \mathrm{g} / \mathrm{mL}$ (Yin et al. 2016)) causes risky problems like vomiting, nausea, blood cell damage, and kidney failure (Behbahani et al. 2014; Zhong et al. 2016). Thus determination of trace amounts of copper in different matrices is of great significance.

\footnotetext{
* Correspondence: Gh_Bagherian@shahroodut.ac.ir; bagherian48@yahoo.com Faculty of Chemistry, Shahrood University of Technology, P.O. Box 36155-316, Shahrood, Iran
}

The most commonly used analytical techniques for determination of metals are graphite furnace atomic absorption spectrometry (GFAAS), flame atomic absorption spectrometry (FAAS), and inductively coupled plasma-optical emission spectrometry (ICP-OES). Nevertheless, because of the matrix interferences and/or the very low concentrations of metal ions, a direct determination of metal ions in water or food samples by the cited techniques is not always attainable (Fan et al. 2017). In order to solve these problems, a preconcentration and matrix elimination step is sometimes needed before applying the cited methods. Different separation and preconcentration techniques like the co-precipitation (Bader and Benkhayal 2014), liquid-liquid extraction (LLE) (Nishihama et al. 2001; Silvestre et al. 2009), and solid-phase extraction (Behbahani et al. 2014; Yin et al. 2016; Khalilian and Rezaee 2017) methods have been developed. However, the mentioned methods are 
laborious, time-consuming, and require a high volume of organic solvents (Khalilian and Rezaee 2016; Quigley et al. 2016). Recently, in order to solve such problems, the dispersive liquid-liquid microextraction (DLLME) technique has been developed by Assadi and co-workers (Rezaee et al. 2006). According to this method, a mixture of an extraction solvent (with a high density) and a disperser solvent (with a high miscibility) is rapidly injected via a syringe into the aqueous phase containing the analyte. During this injection, fine droplets of the extraction solvent dispersed throughout the aqueous sample are formed. At this stage, a cloudy solution is produced. Because of the formation of very small-sized droplets of the extraction solvent, a large surface area is formed between the extraction solvent and the aqueous phase, causing a very quick mass transfer of the analyte from the aqueous phase into the other phase; therefore, the extraction time is very short. The cloudy solution formed is subsequently centrifuged, as a result of which fine droplets are sedimented at the bottom of the conical test tube. Using a syringe, the sedimented phase is removed. The analytes in the enriched phase can then be determined by different analytical methods like GFAAS, FAAS, high-performance liquid chromatography (HPLC), and gas chromatography (GC) (Zhong et al. 2016; Rezaee et al. 2010; El-Shahawi and Al-Saidi 2013; Ming-Jie et al. 2015).

The advantages of the DLLME method are the simplicity of the operation, a short extraction time, a low volume of the organic solvent, a high enhancement factor, low-cost apparatus, and a green method because of the minimizing of consumption of harmful solvents (Özzeybek et al. 2017; Khalilian and Rezaee 2016; Jalbani and Soylak 2015; Reclo et al. 2017; Bahadir et al. 2018; Pouyan et al. 2016). The most significant advantage of these methods is that almost all of the total volume of the extraction phase can be introduced into the detection system, while only a limited volume of the extraction solvent is introduced in the conventional preconcentration and extraction methods (Yilmaz and Soylak 2016).

Thus in the present work, by considering the cited advantages, a new environmentally friendly procedure was developed for the pre-concentration and determination of trace amounts of copper. The method is based on the formation of a complex between $\mathrm{Cu}(\mathrm{II})$ ions and salophen molecules. The complex formed is then transferred into the organic phase using the DLLME technique, and is finally subjected to FAAS detection. Based on our literature survey, up to the present time, no report has been given for the separation and pre-concentration of trace amounts of copper using salophen as the chelating agent.

\section{Experimental}

\section{Instrumentation}

A Shimadzu flame atomic absorption spectrophotometer (model 760AA) equipped with an air-acetylene flame was used for absorbance measurements at a wavelength of $324.8 \mathrm{~nm}$. The instrumental parameters were adjusted according to the manufacturer's recommendations. A Metrohm (model 744) digital $\mathrm{pH}$-meter equipped with a combined glass electrode-calomel $(3 \mathrm{M} \mathrm{KCl})$ was used for the $\mathrm{pH}$ adjustments. A Shimadzu UV-visible spectrophotometer (model UV-160) was used to record the absorption spectra.

\section{Reagents and materials}

2-Hydroxybenzaldehyde (salicylaldehyde) ( $\geq 99.0$ ), 1,2-diaminobenzene (1,2-phenylenediamine) $(\geq 99.0)$, carbon tetrachloride $(\geq 99.0)$, chloroform ( $\geq 99.0$ ), dichloromethane $(\geq 99.0)$, acetone $(\geq 99.5)$, methanol $(\geq 99.5)$, ethanol $(\geq 99.5)$, acetonitrile $(\geq 99.5)$, and potassium nitrate $(\geq$ 99.0) were supplied from Merck (Darmstadt, Germany), and they were used as received. Doubly distilled water was used throughout the work.

A stock standard solution of $\mathrm{Cu}(\mathrm{II})$ ions at a concentration of $1000 \mu \mathrm{g} \mathrm{mL} \mathrm{m}^{-1}$ was prepared from copper(II) sulfate anhydrous ( $\geq 99.0$ ) (Merck), and the working standard solutions were obtained daily by stepwise dilutions of the stock solution with doubly distilled water.

\section{Synthesis of salophen}

$N, N^{\prime}$-bis (salycilidene)-1,2-phenylenediamine (salophen) was synthesized (Mirkhani et al. 2007) and purified in ethanol as what follows.

Salicylaldehyde (2.44g) and 1,2-phenylenediamine $(1.08 \mathrm{~g})$ were dissolved separately in $25 \mathrm{~mL}$ of ethanol. The salicylaldehyde solution was added dropwise to the solution of 1,2-phenylenediamine, and the mixture was refluxed for $3 \mathrm{~h}$. The reaction mixture was then cooled down, and the resulting bright yellow precipitate was separated by filtration. For purification of salophen, the precipitate was dried and recrystallized twice in ethanol. The resulting product (salophen) was characterized by an FT-IR spectrometer, and it had a melting point range of $164-166{ }^{\circ} \mathrm{C}$. A solution of $0.010 \mathrm{M}$ salophen was prepared by dissolution of $0.0790 \mathrm{~g}$ of salophen in acetonitrile and it was diluted in a $25-\mathrm{mL}$ volumetric flask with acetonitrile.

\section{General procedure for analysis}

A $10.0-\mathrm{mL}$ sample solution containing $3.0-120 \mu \mathrm{g} \mathrm{L}^{-1}$ of $\mathrm{Cu}(\mathrm{II})$ ions at $\mathrm{pH}=2.0$ was transferred into a glass test tube with a conical bottom, and $20.0 \mu \mathrm{L}$ of a salophen solution in acetonitrile $(0.010 \mathrm{M})$, used as the chelating agent, was added. Then $1.80 \mathrm{~mL}$ of a mixture of acetone (as the disperser solvent; $1.68 \mathrm{~mL}$ ) and chloroform (as the extraction solvent; $120 \mu \mathrm{L}$ ) was rapidly injected into the sample solution using a syringe, and a stable cloudy solution (water, acetone, and chloroform) was obtained. The resulting $\mathrm{Cu}-$-salophen complex was extracted into 
the fine droplets of chloroform. The mixture was subsequently centrifuged for $5 \mathrm{~min}$ at $5000 \mathrm{rpm}$, and therefore, the extraction solvent (chloroform) containing the analyte was sedimented at the bottom of the conical test tube. The sediment phase $(70 \pm 3 \mu \mathrm{L})$ was then removed using a sampler, transferred into a vial, and diluted with $130 \mu \mathrm{L}$ of ethanol. This solution was subsequently directly introduced into the flame atomic absorption spectrophotometer, and the absorbance of the sample solution was measured against the blank solution. The difference between the absorbance of the sample and blank solutions $\left(\triangle A=A_{\mathrm{s}}-A_{\mathrm{b}}\right)$ at $324.8 \mathrm{~nm}$ was used as an analytical signal. A calibration curve was constructed by plotting the analytical signal versus the $\mathrm{Cu}(\mathrm{II})$ concentration in a series of working standard solutions.

\section{Procedure for obtaining extraction efficiency}

Absorbance of the standard solutions of $\mathrm{Cu}(\mathrm{II})$, prepared in the range of $1.0-10.0 \mu \mathrm{g} \mathrm{mL}^{-1}$, was measured by direct aspiration into the flame atomic absorption spectrometer. The calibration curve was then drawn. Using the analytical signal obtained for each sample after dilution with $130 \mu \mathrm{L}$ ethanol and the calibration curve, the concentration of $\mathrm{Cu}(\mathrm{II})$ ions was determined, and then the mass of copper after DLLME was calculated. The extraction efficiency was then determined in $10.0 \mathrm{~mL}$ of an aqueous solution using the mass of copper before and after DLLME.

To indicate that the analytical signal for the standard solutions in water and that in the chloroform-ethanol mixture were equal, an investigation was carried out. For this purpose, a series of working solutions were prepared, as follows: $20 \mu \mathrm{L}$ of the standard solutions of $\mathrm{Cu}$ (II) ions in the concentration range of $10.0-100.0 \mu \mathrm{g} \mathrm{mL}^{-1}$ was added to a mixture of $60 \mu \mathrm{L}$ of chloroform and $120 \mu \mathrm{L}$ of ethanol. Then the absorbance of these solutions was measured by FAAS. The signals obtained for the standard solutions in the chloroform-ethanol mixture were the same as those obtained for the standard solutions in water.

\section{Results and discussion}

$\mathrm{Cu}$ (II) ions reacted with salophen, and a complex was formed between them under the experimental conditions (Fig. 1) (Zeeb et al. 2011). The Cu-salophen complex in an acidic medium was extracted into the organic solvent. To reach a high analytical signal and enrichment factor, the effects of different parameters such as the solution $\mathrm{pH}$, type and volume of the extraction solvent, type and volume of the disperser solvent, and concentration of the chelating agent were optimized. For optimization of the above-mentioned parameters, the univariate optimization strategy was used.

\section{Effect of $\mathrm{pH}$}

The $\mathrm{pH}$ value plays an important role in the formation of the $\mathrm{Cu}$-salophen complex and the subsequent extraction. For this reason, a series of experiments were carried out by adjusting the $\mathrm{pH}$ value from 1.5 to 7.0 . The results obtained (Fig. 2) show that the analytical signal for copper is nearly constant in the $\mathrm{pH}$ range of 1.5-4. Thus based upon the results obtained and to obtain a high selectivity, $\mathrm{pH}=2.0$ was chosen as the optimum $\mathrm{pH}$.

\section{Selection of extraction solvent}

The type of the extraction solvent has a significant effect on the extraction efficiency. The extraction solvent must have a low solubility in water, its density should be higher than water, and the solvent should have the ability to extract the compounds of interest (Naseri et al. 2008). In this regard, the efficiencies of different solvents such as carbon tetrachloride, chloroform, and dichloromethane were investigated. Since the solubility of the extraction solvents in water are different, it was necessary to add an excess amount of the extraction solvent in

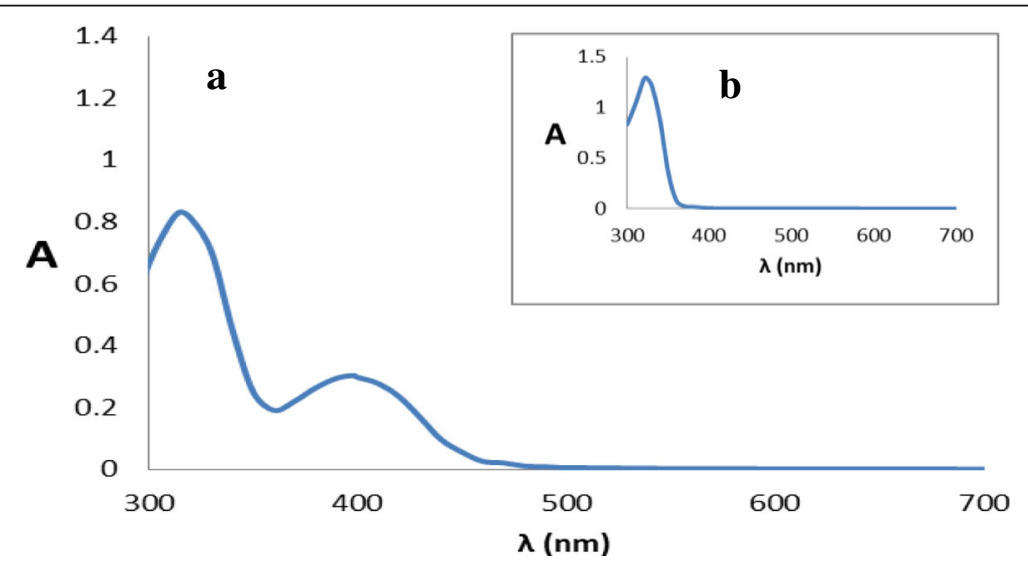

Fig. 1 The absorption spectra for a Cu-salophen complex and $\mathbf{b}$ salophen ligand. Conditions: a $\mathrm{Cu}(\mathrm{II})$ concentration, $5.0 \times 10^{-5} \mathrm{M}$; salophen concentration, $2.5 \times 10^{-4} \mathrm{M}$; solvent, water; $\mathrm{pH}=2.0$; b salophen concentration, $2.5 \times 10^{-4} \mathrm{M}$; solvent, water; $\mathrm{pH}=2.0$ 


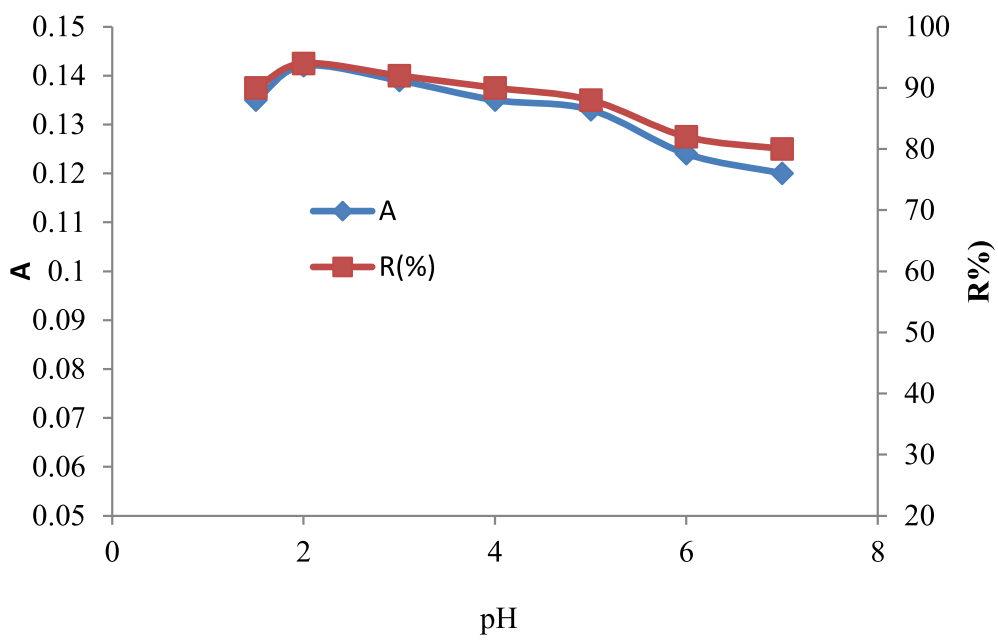

Fig. 2 Effect of solution pH on the extraction of $\mathrm{Cu}(\mathrm{II})$ ions by DLLME method. Conditions: sample volume, $10.0 \mathrm{~mL}$; $\mathrm{Cu}(\mathrm{II})$ ion concentration, $50.0 \mu \mathrm{g} \mathrm{L}^{-1}$, salophen concentration, $2.0 \times 10^{-5} \mathrm{M}$; extraction solvent (chloroform) volume, $110 \mu \mathrm{L}$; disperser solvent (acetone) volume, $1.30 \mathrm{~mL}$; diluting solvent (ethanol) volume, $140 \mu \mathrm{L}$; centrifuge time, $5 \mathrm{~min}$ (at $5000 \mathrm{rpm}$ )

order to recover a constant volume of the sedimented phase $(60 \pm 3 \mu \mathrm{L})$. Therefore, 80,110 , and $140 \mu \mathrm{L}$ of carbon tetrachloride, chloroform, and dichloromethane with $1.30 \mathrm{~mL}$ of acetone (as the disperser solvent) were separately injected into $10.0 \mathrm{~mL}$ of the sample solutions to achieve a total volume of $60 \mu \mathrm{L}$ of the sedimented phase. The results obtained (Fig. 3) showed that the extraction efficiencies of carbon tetrachloride, chloroform, and dichloromethane were $58 \%$, $94 \%$, and $51 \%$, respectively. Consequently, chloroform was selected as the best extraction solvent.

\section{Effect of extraction solvent volume}

The effect of the extraction solvent volume was also investigated by preparing mixtures of $1.30 \mathrm{~mL}$ of acetone and different volumes of chloroform. The results obtained are shown in Table 1. As it can be seen in this table, the analytical signal and the extraction efficiency were nearly constant in the volume range of $70-120 \mu \mathrm{L}$ of chloroform, and then they gradually decreased. This is due to the fact that for an extraction solvent volume more than $120 \mu \mathrm{L}$, the resulting cloudy solution was not stable, and the size of chloroform droplets was large. Therefore, the surface area between the extraction solvent and the aqueous phase decreased, causing a decrease in the mass transfer and an efficient extraction of the $\mathrm{Cu}$-salophen complex from the aqueous phase into chloroform. Thus to ensure an enough chloroform volume for extraction of a higher concentration of copper, $120 \mu \mathrm{L}$ of chloroform was selected as the optimum volume, and the sedimented phase was $70 \mu \mathrm{L}$.

It should be noted that in studying the effect of the extracting solvent volume, since the volume of the

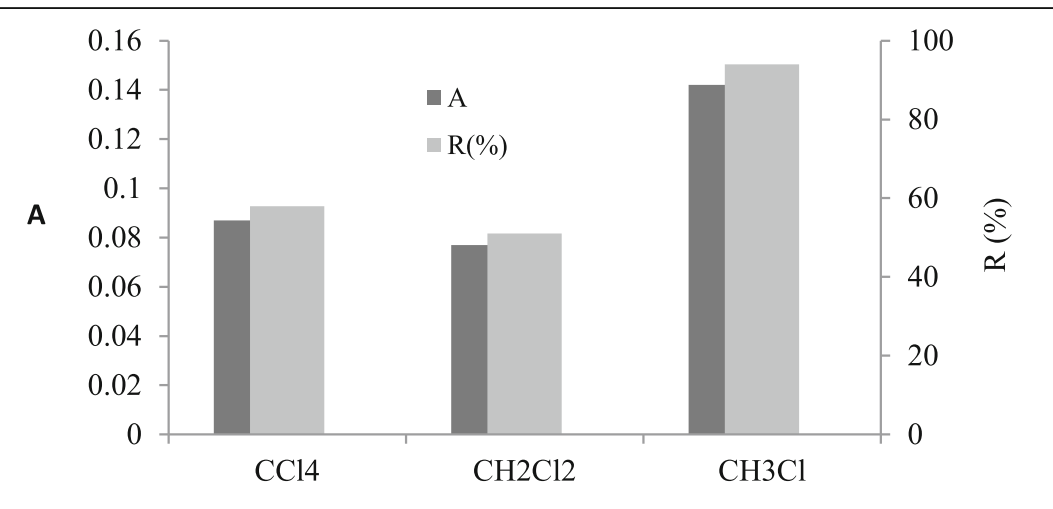

Solvent

Fig. 3 Effect of the extraction solvent on the extraction of $\mathrm{Cu}(\mathrm{II})$ ions by DLLME method. Conditions: sample volume, $10.0 \mathrm{~mL} ; \mathrm{Cu}(\mathrm{II})$ ion concentration, $50.0 \mathrm{~m} \mathrm{~L}^{-1}$, solution $\mathrm{pH}=2.0$; salophen concentration, $2.0 \times 10^{-5} \mathrm{M}$; disperser solvent (acetone) volume, $1.30 \mathrm{~mL}$; diluting solvent (ethanol) volume, $140 \mu \mathrm{L}$; centrifuge time, $5 \mathrm{~min}$ (at $5000 \mathrm{rpm}$ ) 
Table 1 Effect of extraction solvent (chloroform) volume on the analytical signal and extraction efficiency of copper obtained from DLLME

\begin{tabular}{lllll}
\hline $\begin{array}{l}\text { Chloroform } \\
(\mu \mathrm{L})\end{array}$ & $\begin{array}{l}\text { Sedimented } \\
\text { phase }(\mu \mathrm{L})\end{array}$ & $\begin{array}{l}\text { Ethanol as diluting } \\
\text { solvent }(\mu \mathrm{L})\end{array}$ & $A_{\mathrm{Cu}}$ & $\begin{array}{l}\text { Extraction } \\
\text { Efficiency }(\%)\end{array}$ \\
\hline 70 & 20 & 180 & 0.142 & 94 \\
100 & 50 & 150 & 0.142 & 94 \\
110 & 60 & 140 & 0.141 & 94 \\
120 & 70 & 130 & 0.143 & 95 \\
150 & 100 & 100 & 0.105 & 70 \\
170 & 120 & 80 & 0.100 & 66 \\
200 & 160 & 40 & 0.080 & 53 \\
\hline
\end{tabular}

Conditions: sample volume, $10.0 \mathrm{~mL}$; $\mathrm{Cu}(\mathrm{II}), 50.0 \mu \mathrm{g} \mathrm{L}^{-1}$; solution $\mathrm{pH}=2.0$; salophen, $2.0 \times 10^{-5} \mathrm{M}$; disperser solvent (acetone) volume, $1.30 \mathrm{~mL}$; diluting solvent, ethanol; centrifuge time, $5 \mathrm{~min}$ (at $5000 \mathrm{rpm}$ )

sedimented phase was variable, the solutions were diluted up to $200 \mu \mathrm{L}$ using different volumes of ethanol, as the diluting solvent. Therefore, it was necessary to investigate the effect of the volume of the diluting solvent on the analytical signal. In this regard, in a series of $10.0 \mathrm{~mL}$ water samples at $\mathrm{pH}=2.0$ containing $50.0 \mu \mathrm{g} \mathrm{L}$ of $\mathrm{Cu}(\mathrm{II})$ ions, the $\mathrm{Cu}$-salophen complex was extracted by injecting a mixture containing $1.30 \mathrm{~mL}$ of acetone and $120 \mu \mathrm{L}$ of chloroform. After centrifugation, $50.0 \mu \mathrm{L}$ of the sedimented phase was transferred into a vial, to which were added $0.0,20,40,60$, and $80 \mu \mathrm{L}$ of chloroform. Then 150, 130, 110, 90, and $70 \mu \mathrm{L}$ ethanol, respectively, were added to the above-mentioned solutions until the total volumes of $200 \mu \mathrm{L}$ were reached. These solutions were aspirated to FAAS. The results obtained were the same (Table 2). Thus the changes in the ratio of volume of the sedimented phase to volume of ethanol had no effect on the analytical signal.

\section{Selection of disperser solvent}

In the DLLME method, the disperser solvent should be miscible with water and the extraction solvent.
Therefore, the effect of miscible solvents such as acetone, methanol, ethanol, and acetonitrile on the analytical signal (extraction efficiency) of $\mathrm{Cu}(\mathrm{II})$ ions was investigated using mixtures of $1.30 \mathrm{~mL}$ of the above-mentioned solvents (as the disperser solvent) and $120.0 \mu \mathrm{L}$ of $\mathrm{CHCl}_{3}$ (as the extraction solvent). The analytical signals (extraction efficiencies) obtained for acetone, methanol, ethanol, and acetonitrile were 0.140 (94\%), 0.108 (72\%), $0.118(78 \%)$, and 0.098 (65\%), respectively (Fig. 4). The maximum analytical signal (extraction efficiency) of $\mathrm{Cu}(\mathrm{II})$ ions was obtained using acetone, as the disperser solvent. Thus acetone was used as the disperser solvent in all the subsequent experiments.

\section{Effect of disperser solvent volume}

After selecting acetone as the disperser solvent, its volume is one of the important factors involved in DLLME that must be optimized. For this purpose, solutions with different volumes of acetone $(0.88-1.88 \mathrm{~mL})$ containing $120 \mu \mathrm{L}$ of $\mathrm{CHCl}_{3}$ were prepared and subjected to the similar DLLME procedures. The results obtained (Fig. 5) showed that the analytical signal (extraction efficiency) increased with increase in the volume of acetone up to $1.50 \mathrm{~mL}$, after which it remained constant. When a low volume of acetone was used, it could not disperse $\mathrm{CHCl}_{3}$ properly, and a stable cloudy solution was not formed. Consequently, the extraction efficiency was reduced. However, with a gradual increase in the disperser solvent volume, due to the formation of smaller droplets of chloroform, the surface area between the extraction solvent and the aqueous phase increased. This phenomenon led to an increase in the extraction efficiency. Therefore, based on the results obtained and in order to create a more stable cloudy solution, $1.68 \mathrm{~mL}$ of acetone was selected as the optimal volume.

\section{Effect of salophen concentration}

The effect of the concentration of salophen, as the complexing agent, on the analytical signal in the extraction

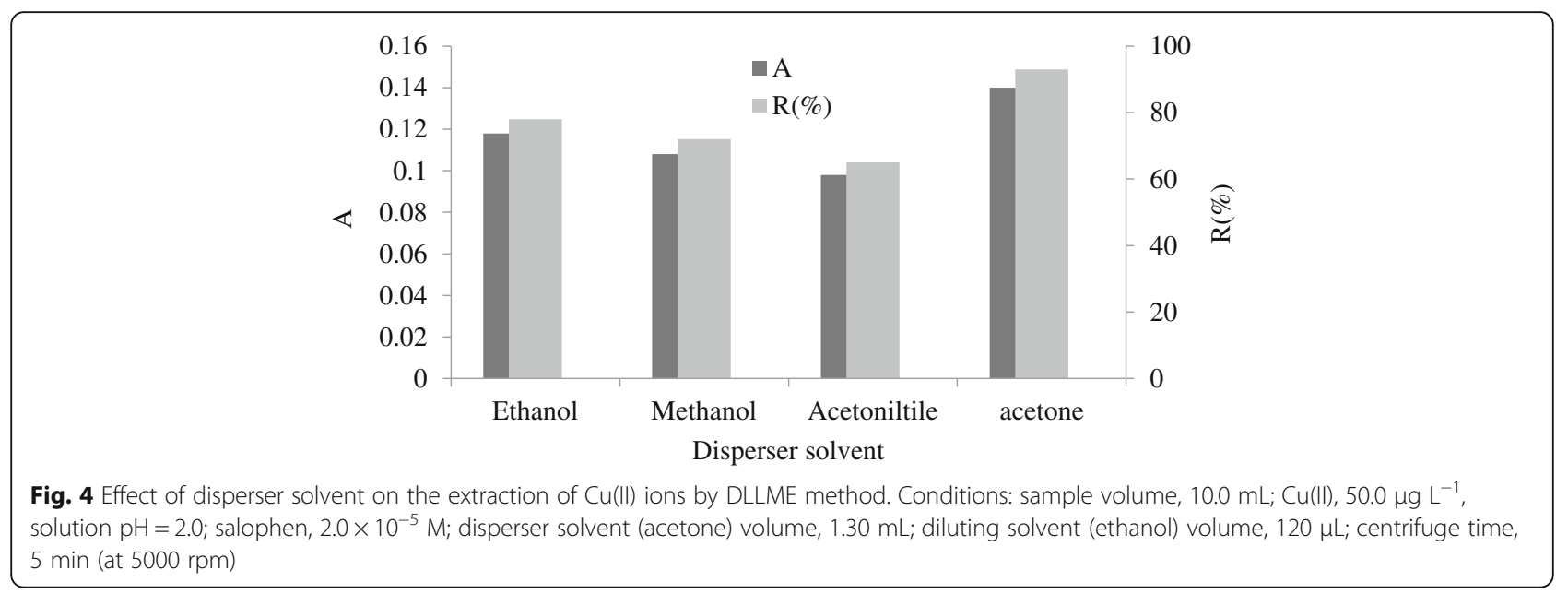




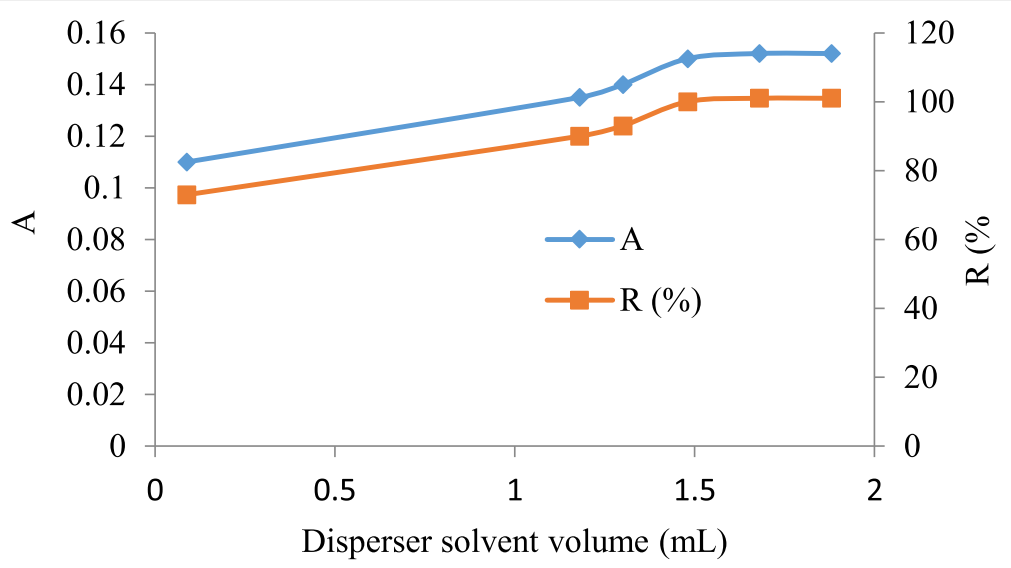

Fig. 5 Effect of disperser solvent volume on the extraction of $\mathrm{Cu}(\mathrm{II})$ ions by DLLME method. Conditions: sample volume, $10.0 \mathrm{~mL}$; $\mathrm{Cu}(\mathrm{II})$, $50.0 \mathrm{Mg} \mathrm{L}^{-1}$; solution $\mathrm{pH}=2.0$; salophen concentration, $2.0 \times 10^{-5} \mathrm{M}$; diluting solvent, ethanol; centrifuge time, $5 \mathrm{~min}$ (at $5000 \mathrm{rpm}$ )

of $\mathrm{Cu}$ (II) ions by DLLME was studied in the concentration range of $5.0 \times 10^{-6}-3.0 \times 10^{-5} \mathrm{M}$. The results obtained showed that the signal for $\mathrm{Cu}(\mathrm{II})$ ions increased with increase in the salophen concentration up to $1.5 \times$ $10^{-5} \mathrm{M}$, and then it remained constant (Fig. 6). In this work, a salophen concentration of $2.0 \times 10^{-5} \mathrm{M}$ was chosen as the optimum concentration to prevent any interference.

\section{Effect of reaction time for complex formation}

The reaction time for the complex formation can be defined as the time spent between the addition of salophen solution to the sample solution and injection of the extraction solvent (chloroform) dissolved in the disperser solvent (acetone). This was studied in the time range of 0-15 min (Fig. 7). The results obtained showed that the reaction was fast, and so the reaction time did not have any effect on the analytical signal.
Effects of extraction time and centrifugation time

The extraction time is one of the most important factors involved in all the extraction procedures. In DLLME, the extraction time is defined as the interval time between the injection of the mixture of organic solvents (disperser and extraction solvents) and starting the centrifugation. The effect of the extraction time was evaluated in the range of 1-20 min under constant experimental conditions. The results obtained (Fig. 8) indicated that the extraction time had no significant influence on the analytical signal. These results showed that after formation of the cloudy solution, the surface area between the extraction solvent and the aqueous phase was infinitely large and that the resulting $\mathrm{Cu}(\mathrm{II})$-salophen complex was transferred into the extraction solvent quickly. Therefore, the proposed DLLME method is time-independent, which can be one of its most important advantages.

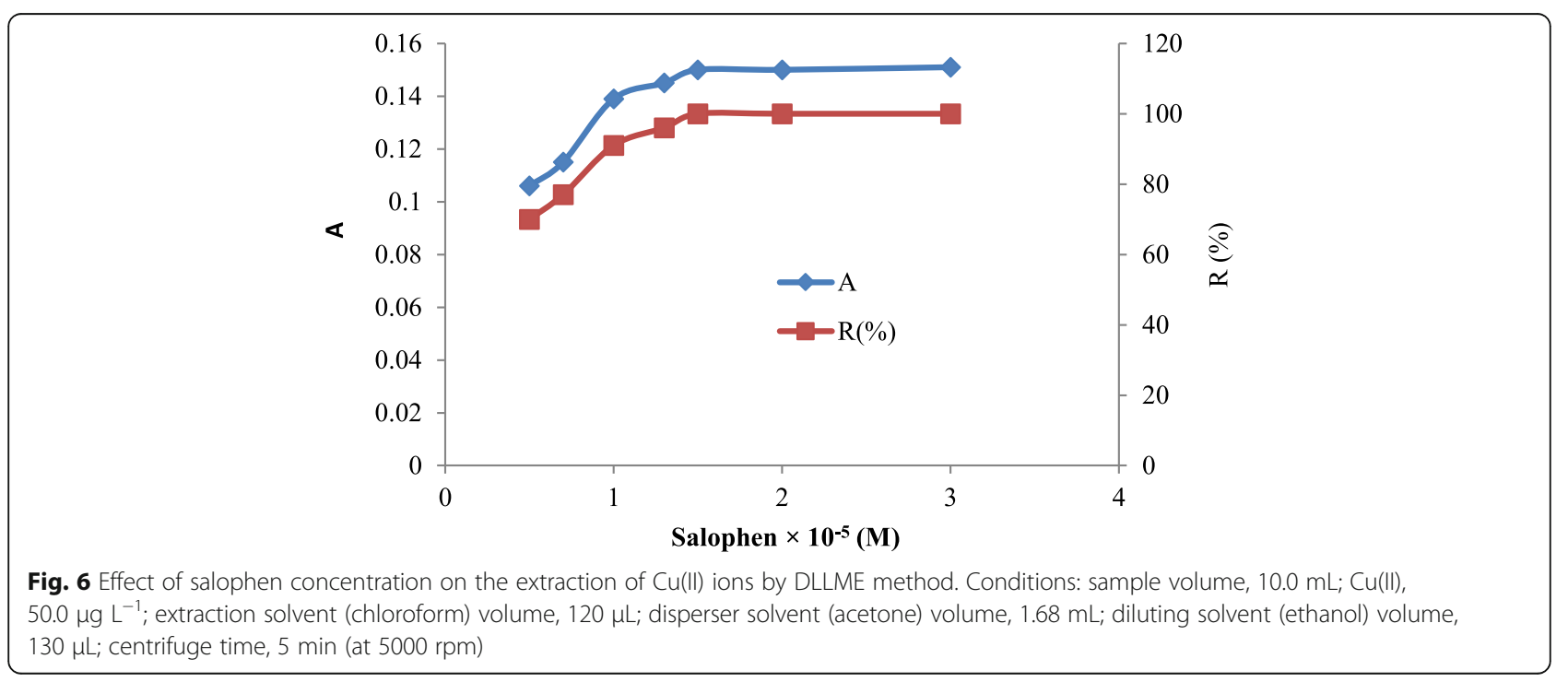




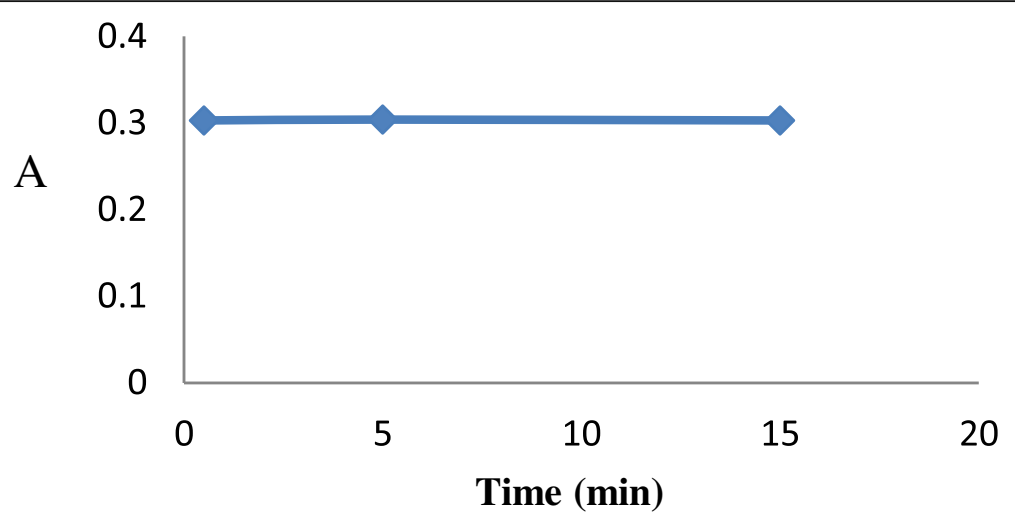

Fig. 7 Effect of reaction time on the complex formation

The centrifugation time was also evaluated to be between 1 and $10 \mathrm{~min}$ at $5000 \mathrm{rpm}$. The results obtained showed that the analytical signal increased with increase in the centrifugation time up to $3 \mathrm{~min}$, and then it remained constant, indicating a complete separation of chloroform to the bottom of the centrifuge tube. In order to ensure sedimentation (complete separation) of the extraction solvent, a time duration of 5 min was selected as the centrifugation time in all the further experiments. In the proposed method, the most timeconsuming step was the centrifugation of the sample solution in the extraction procedure.

\section{Effect of ionic strength}

The influence of ionic strength on the extraction of the $\mathrm{Cu}$-salophen complex was studied using potassium nitrate as a salting-out agent at the concentration range of $0-1.0 \mathrm{M}$. The results obtained showed that the salt concentration had no influence on the analytical signal (extraction efficiency). In all concentrations of $\mathrm{KNO}_{3}$, the extraction efficiency was $100 \%$ (Fig. 9). These results implied the possibility of applying the DLLME method for copper separation from salty solutions.

\section{Study of interferences}

The FAAS technique has a high selectivity but some species may interfere with the extraction step and change the extraction efficiency of copper. In order to investigate the effect of the potential interfering ions, solutions containing $50.0 \mu \mathrm{g} \mathrm{\textrm {L } ^ { - 1 }}$ of $\mathrm{Cu}(\mathrm{II})$ ions and different amounts of foreign ions were treated according to the recommended procedure. The tolerable concentration of foreign ions was considered, i.e., the concentration at which less than $\pm 5 \%$ deviation in the analytical signal was measured in comparison with the case in which the interfering ion was absent. The results obtained are summarized in Table 3. These results showed that most ions did not interfere even if they were present in amounts 1000 -fold greater or more than copper.

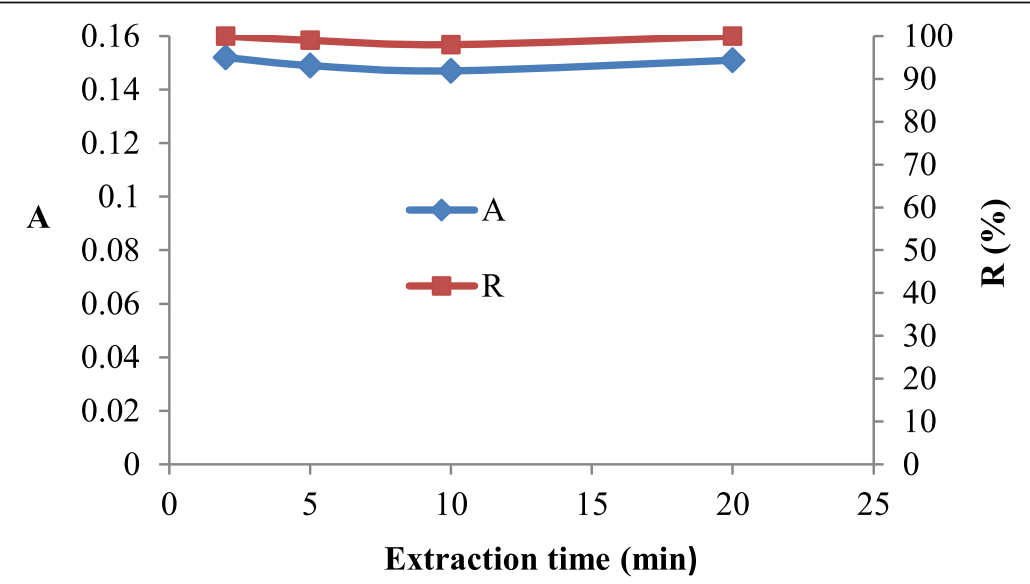

Fig. 8 Effect of extraction time on the extraction of $\mathrm{Cu}(\mathrm{II})$ ions by DLLME method. Conditions: sample volume, $10.0 \mathrm{~mL} ; \mathrm{Cu}(\mathrm{II}), 50.0 \mu \mathrm{g} \mathrm{L}{ }^{-1}$; salophen concentration, $2.0 \times 10^{-5} \mathrm{M}$; extraction solvent (chloroform) volume, $120 \mu \mathrm{L}$; disperser solvent (acetone) volume, $1.68 \mathrm{~mL}$; diluting solvent (ethanol) volume, $130 \mu \mathrm{L}$; centrifuge time, $5 \mathrm{~min}$ (at $5000 \mathrm{rpm}$ ) 


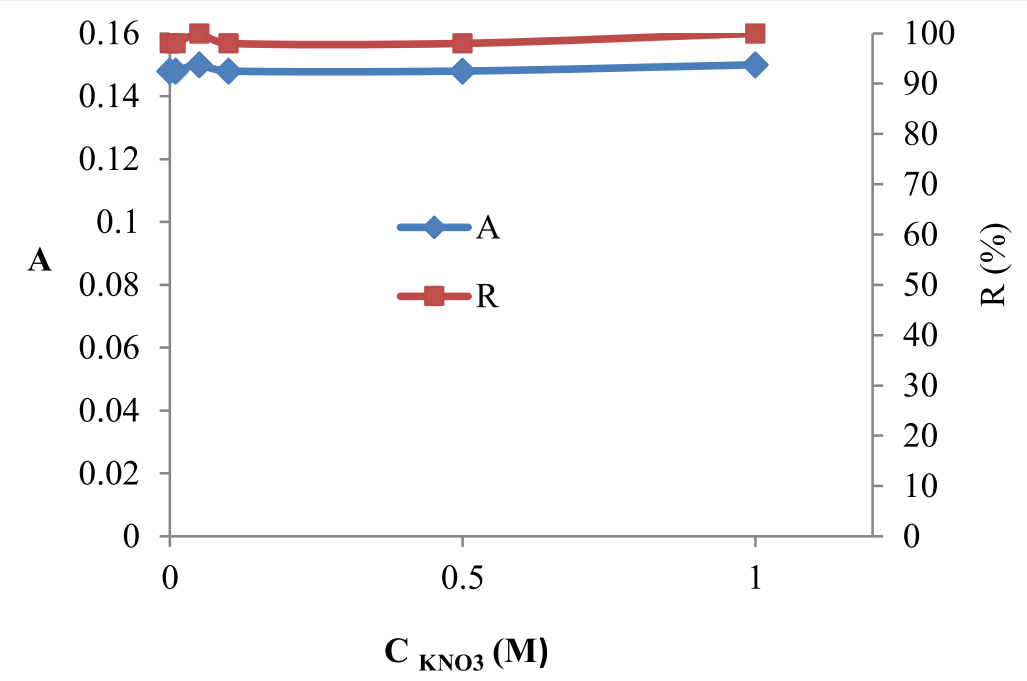

Fig. 9 Effect of ionic strength on the extraction of $\mathrm{Cu}(\mathrm{II})$ ions by DLLME method. Conditions: sample volume, $10.0 \mathrm{~mL} ; \mathrm{Cu}(\mathrm{II}), 50.0 \mu \mathrm{g} \mathrm{L}{ }^{-1}$, extraction solvent (chloroform) volume, $120 \mu \mathrm{L}$; disperser solvent (acetone) volume, $1.68 \mathrm{~mL}$; diluting solvent (ethanol) volume, $130 \mu \mathrm{L}$; centrifuge time, 5 min (at $5000 \mathrm{rpm}$ )

The $\mathrm{Hg}^{2+}, \mathrm{Sn}^{2+}$, and $\mathrm{Pb}^{2+}$ ions reacted with the phosphate ions (i.e., the ion of buffer solution) and precipitated.

\section{Analytical parameters}

The analytical characteristics of the proposed method were calculated under the optimized conditions. For a sample volume of $10.0 \mathrm{~mL}$, the calibration curve exhibited a linearity over the range of $3.0-120 \mu \mathrm{g} \mathrm{L}^{-1}$ under the optimum conditions. The regression equation for copper determination was $\Delta A=2.9003 \mathrm{C}+1.8 \times 10^{-2}$, where $\Delta A$ is the analytical signal (the difference between the absorbance of the sample and blank solutions $(\triangle A=$ $\left.A_{\mathrm{s}}-A_{\mathrm{b}}\right)$ at $324.8 \mathrm{~nm}$ ) and $\mathrm{C}$ is the copper(II) ion concentration in solution $\left(\mu \mathrm{g} \mathrm{mL} \mathrm{m}^{-1}\right)$. The correlation coefficient $\left(R^{2}\right)$ of the calibration curve equation obtained was 0.9998, which indicated a good linearity in the

Table 2 Results of investigation of the effect of the ratio of volume of the sedimented phase to volume of ethanol (diluting solvent) on the analytical signal of Cu(II) determined by DLLME

\begin{tabular}{llll}
\hline $\begin{array}{l}\text { Volume of sedimented } \\
\text { phase }(\mu \mathrm{L})\end{array}$ & $\begin{array}{l}\text { Added volume of } \\
\text { chloroform }(\mu \mathrm{L})\end{array}$ & $\begin{array}{l}\text { Added volume } \\
\text { of ethanol }(\mu \mathrm{L})\end{array}$ & $A_{\mathrm{Cu}}$ \\
\hline 50 & 0.0 & 150 & 0.106 \\
50 & 20 & 130 & 0.104 \\
50 & 40 & 110 & 0.107 \\
50 & 60 & 90 & 0.105 \\
50 & 80 & 70 & 0.104 \\
\hline Conditions: sample volume, & $10.0 \mathrm{~mL} \cdot \mathrm{Cu}(\mathrm{III}), 50.0 \mathrm{\mu g} \mathrm{L}^{-1}$. solution $\mathrm{pH}=2.0$
\end{tabular}

Conditions: sample volume, $10.0 \mathrm{~mL}$; $\mathrm{Cu}(\mathrm{II}), 50.0 \mu \mathrm{g} \mathrm{L}^{-1}$; solution $\mathrm{pH}=2.0$; salophen, $2.0 \times 10^{-5} \mathrm{M}$; disperser solvent (acetone) volume, $1.30 \mathrm{~mL}$; diluting solvent, ethanol; centrifuge time, 5 min (at $5000 \mathrm{rpm}$ ) mentioned concentration range. The limit of detection based on a signal-to-noise ratio of $3(3 \sigma)$ was $0.6 \mu \mathrm{g} \mathrm{L}^{-1}$. The equation obtained by direct aspiration in FAAS without the preconcentration procedure was $\triangle A=0.059$ $\mathrm{C}+1.3 \times 10^{-2}\left(R^{2}=0.9997\right.$ and a linear range of 0.250 $10.0 \mu \mathrm{g} \mathrm{mL}^{-1}$ ). The enrichment factor (EF), calculated as the ratio of the slope of calibration curve of the analytes after extraction to that before extraction (Şatıroğlu and Arpa 2008), was found to be 49 for $10.0 \mathrm{~mL}$ of the sample solution.

Based on the organic phase volume $(200 \mu \mathrm{L})$ and the sample volume $(10.0 \mathrm{~mL})$, a preconcentration factor of 50 was determined. The equality of the preconcentration factor and the enrichment factor indicates the completion of the quantitative extraction.

Since in the reported methods different volumes of the sample solution were used, the enrichment factors

Table 3 Tolerance limits for interferences in determination of $50.0 \mu \mathrm{g} \mathrm{L}^{-1} \mathrm{Cu}(\mathrm{II})$ ions

\begin{tabular}{|c|c|}
\hline Foreign species & $\begin{array}{l}\text { Tolerated ratio } \\
\left(W_{\text {species }} / W_{\text {Cu(II) }}\right)\end{array}$ \\
\hline $\begin{array}{l}\mathrm{NO}_{3}^{-}, \mathrm{Cl}^{-}, \mathrm{BrO}_{3}{ }^{-}, \mathrm{ClO}_{4}^{-}, \mathrm{S}_{2} \mathrm{O}_{8}{ }^{2-}, \mathrm{Cr}^{3+}, \\
\mathrm{Cr}^{6+}, \mathrm{Mn}^{2+}, \mathrm{Li}^{+}, \mathrm{Co}^{2+}, \mathrm{K}^{+}, \mathrm{Al}^{3+}, \mathrm{Pd}^{2+}, \\
\mathrm{Ni}^{2+}, \mathrm{Ag}^{+}\end{array}$ & 5000 \\
\hline $\begin{array}{l}\mathrm{PO}_{4}{ }^{3-}, \mathrm{IO}_{4}{ }^{-}, \mathrm{F}^{-}, \mathrm{SO}_{3}{ }^{2-}, \text { citrate, } \mathrm{S}_{2} \mathrm{O}_{5}{ }^{2-}, \\
\mathrm{SCN}^{-}, \mathrm{CN}^{-}, \mathrm{HCOO}^{-}, \text {acetate, } \mathrm{CO}_{3}{ }^{2-}, \\
\mathrm{C}_{2} \mathrm{O}_{4}{ }^{2-}, \mathrm{Ba}^{2+}, \mathrm{Zn}^{2+}, \mathrm{Fe}^{2+}, \mathrm{Fe}^{3+}\end{array}$ & 1000 \\
\hline $\mathrm{ClO}_{3}^{-}, \mathrm{NO}_{2}^{-}, \mathrm{Cd}^{2+}$ & 500 \\
\hline $\mathrm{Hg}^{2+}$ & 100 \\
\hline $\mathrm{Sn}^{2+}, \mathrm{Pb}^{2+}$ & 10 \\
\hline
\end{tabular}


obtained in these methods are not compared. Therefore, the consumption factor is preferred on the enrichment factor. The consumptive index $(\mathrm{CI})$ is defined as the aqueous sample volume (in $\mathrm{mL}$ ) consumed to reach a unit of $\mathrm{EF}: \mathrm{CI}=\mathrm{Vs} / \mathrm{EF}$, where $\mathrm{Vs}$ is the aqueous sample volume (Lemos et al. 2007). For the proposed method, this parameter was obtained to be $0.20 \mathrm{~mL}$. A low value for this parameter indicates a favorable efficiency of the method.

In order to investigate the reproducibility of the proposed method, six replicate measurements of 5.0, 20.0, and $50.0 \mu \mathrm{g} \mathrm{L}^{-1}$ of $\mathrm{Cu}(\mathrm{II})$ ions gave the relative standard deviations of $4.1 \%, 1.5 \%$, and $1.8 \%$, respectively.

A summary of the analytical characteristics of the DLLME method for copper determination is presented in Table 4 .

\section{Analysis of real samples Analysis of water samples}

The proposed method was applied to determine $\mathrm{Cu}(\mathrm{II})$ ions in samples of tap water (Shahrood and Jajarm, Iran) and spring water (Ali spring in Damghan, Iran) by the standard addition technique. The recoveries of copper from the water samples spiked with $\mathrm{Cu}$ (II) ions were also studied. The results obtained are shown in Table 5 . Satisfactory recoveries were obtained for the spiked copper(II) ions, confirming the accuracy and applicability of the proposed DLLME-FAAS method for copper determination in water samples.

\section{Analysis of a rice sample}

In order to evaluate the applicability of the proposed method for determination of copper in food samples, a type of rice from the north of Iran was selected and analyzed. For this purpose, $10.00 \mathrm{~g}$ of the rice was dissolved according to the procedure reported by Zeeb et al. 2011 and transferred into a $100-\mathrm{mL}$ volumetric flask. Then, $20.0 \mathrm{~mL}$ of the prepared rice sample solution, $1.25 \mathrm{~mL}$ of the phosphate buffer solution ( $\mathrm{pH}=2.0)$, and $50 \mu \mathrm{L}$ of the salophen solution $(0.010 \mathrm{M})$ were transferred into a $25-\mathrm{mL}$ volumetric flask and diluted to the mark with

Table 4 Analytical characteristics of the DLLME-FAAS method for copper determination

\begin{tabular}{ll}
\hline Parameter & Analytical feature \\
\hline Sample consumption $(\mathrm{mL})$ & 10.0 \\
Linear range $\left(\mu \mathrm{g} \mathrm{L}^{-1}\right)$ & $3.0-120$ \\
Regression eq. $\left(\mathrm{C}\right.$ in $\left.\mu \mathrm{g} \mathrm{mL}^{-1}, n=9\right)$ & $\Delta \mathrm{A}=2.9003 \mathrm{C}+1.8 \times 10^{-2}$ \\
Limit of detection, $\mu \mathrm{g} \mathrm{L}^{-1}(3 \sigma)$ & 0.60 \\
Preconcentration factor & 50 \\
Enrichment factor & 49 \\
Precision (20.0 $\left.\mu \mathrm{g} \mathrm{mL}{ }^{-1}, n=6\right) \mathrm{RSD}(\%)$ & 1.5 \\
Consumptive index $(\mathrm{mL})$ & 0.20 \\
Recovery (\%) & $96-105$ \\
\hline
\end{tabular}

Table 5 Determination of copper in water samples

\begin{tabular}{lllll}
\hline Sample & $\begin{array}{l}\text { Added, } \\
\mu \mathrm{L} \mathrm{L}^{-1}\end{array}$ & $\begin{array}{l}\text { Found, } \\
\mu \mathrm{L}^{-1}\end{array}$ & $\begin{array}{l}\text { RSD (\%), } \\
n=3\end{array}$ & $\begin{array}{l}\text { Recovery } \\
(\%)\end{array}$ \\
\hline Tap water (1) & - & $<\mathrm{LOD}$ & & \\
& 10.0 & 9.6 & 3.3 & 96 \\
& 20.0 & 19.0 & 2.6 & 95 \\
& 50.0 & 50.3 & 1.2 & 101 \\
Tap water (2) & - & $<\mathrm{LOD}$ & & \\
& 10.0 & 10.2 & 5.0 & 102 \\
& 20.0 & 19.5 & 1.1 & 97 \\
& 50.0 & 50.3 & 1.2 & 101 \\
Spring water & & $<\mathrm{LOD}$ & & \\
& 10.0 & 9.6 & 3.7 & 96 \\
& 20.0 & 19.2 & 2.7 & 96 \\
& 50.0 & 50.0 & 2.6 & 100 \\
\hline
\end{tabular}

doubly distilled water. The concentration of copper in $10.0 \mathrm{~mL}$ of this solution was determined by the proposed method using the standard curve technique. The results of the recovery experiments for different amounts of $\mathrm{Cu}$ are summarized in Table 6 . These results indicate that the recoveries in the range of $96-105 \%$ are reasonably well for trace analysis, and the calculated $t$ values are less than the $t$-critical values at the $95 \%$ confidence level. The results obtained confirm the validity of the developed method.

\section{Conclusion}

In the present work, the performance of an environmentally friendly method for the preconcentration and determination of ultra-trace amounts of $\mathrm{Cu}(\mathrm{II})$ ions has been investigated. This method is based upon the formation of complex between $\mathrm{Cu}(\mathrm{II})$ ions with salophen as a ligand, followed by DLLME of the neutral hydrophobic complex formed in the organic phase and flame atomic absorption spectrophotometric detection. The main advantages of the proposed method are its high selectivity, simplicity, low consumption of organic solvent, and rapidity. A comparison between the analytical figures of merit for the developed method and some of the other preconcentration methods combined with flame atomic

Table 6 Results for determination of $\mathrm{Cu}(\mathrm{II})$ ions in rice sample

\begin{tabular}{lllll}
\hline Sample & $\begin{array}{l}\text { Added, } \\
\mu \mathrm{g} \mathrm{L}^{-1}\end{array}$ & $\begin{array}{l}\text { Found }^{\mathrm{a}}, \\
\mu \mathrm{g} \mathrm{L}^{-1}\end{array}$ & $\begin{array}{l}\text { Recovery } \\
(\%)\end{array}$ & $\begin{array}{l}\text { Content in } \\
\text { rice } \mu \mathrm{g} \mathrm{g}^{-1}\end{array}$ \\
\hline Rice & - & $7.5( \pm 0.6)$ & & $0.094( \pm 0.008)$ \\
& 10.0 & $18.0( \pm 0.4)$ & 105 & \\
30.0 & $38.2( \pm 0.5)$ & 102 & \\
60.0 & $65.5( \pm 1.5)$ & 96.7 &
\end{tabular}

${ }^{a}$ Numbers in parentheses are standard deviations for three replicate measurements 
Table 7 Comparison between the developed method and some preconcentration methods combined with flame atomic absorption spectrometry

\begin{tabular}{llllllll}
\hline $\begin{array}{l}\text { Preconcentration } \\
\text { method }\end{array}$ & Chelating agent & Disperser & Extraction phase & LOD $\left(\mu \mathrm{g} \mathrm{L}^{-1}\right)$ & PF or EF & Cl (mL) & Ref. \\
\hline CPE & Me-BDBD & & Triton X-114 & 1.5 & 14 & 0.71 & Lemos et al. 2007 \\
CPE & ARS & - & Triton X-114 & 1.07 & 21 & 0.57 & Şatığlu and Arpa 2008 \\
CPE & Br-PADAP & - & Triton X-114 & 1.5 & 25 & 2.0 & Xu et al. 2013 \\
DLLME & HOX & Methanol & Chloroform & 3.0 & 42 & 0.24 & Farajzadeh et al. 2008 \\
DLLME & - & Ethanol & 1,2-DCB & 0.50 & - & - & Mohammadi et al. 2009 \\
IL-DLLME & TMK & Acetone & ([Hmim][Tf2N] & 0.45 & 136.6 & 0.073 & Khani et al. 2011 \\
UA-IL-DLLME & H2L & Acetone & [HMIM][PF6] & 1.9 & 56 & 0.18 & Rajabi et al. 2014 \\
SS-LPME & PAN & - & Triethylamine & 1.8 & 25 & 0.85 & Yilmaz and Soylak 2015 \\
SS-LLME & Dimethyl & - & 1-decanol & 0.52 & 53 & 0.19 & Yilmaz and Soylak 2014 \\
& dithiocarbamate & & & & 49 & 0.20 & This work
\end{tabular}

PF preconcentration factor, EF efficiency factor, Cl consumptive index, LOD limit of detection, CPE cloud point extraction, DLLME dispersive liquid-liquid microextraction UA-IL-DLLME ultrasound-assisted ionic liquid-based dispersive liquid-liquid microextraction, SS-LPME switchable solvent-based liquid-phase microextraction, Ss-LLME Supramolecular solvent-based liquid-liquid microextraction, Br-PADAP 2-(5-bromo-2-pyridylazo)-5-(diethylamino)phenol, 1,2-DCB 1,2-dicholorobenzene, Me-BDBD 6-[20(60-methyl-benzothiazolylazo)]-1,2-dihydroxy-3,5-benzenedisulfonic acid, ARS Alizarin Red S, [Hmim][Tf2N] 1-hexyl-3-methylimmidazolium bis(trifluormethylsulfonyl)imid, TMK 4,4'-bis(dimethylamino)thiobenzophenone, [HMIM][PF6] 1-hexyl-3-methylimidazolium hexafluorophosphate, H2L N,N'-bis(2-salicylaldiminato)-1,8-diamino-3,6dioxaoctane, HOX 8-hyroxyquinolone, PAN 1-(2-pyridylazo)-2 naphthol, Salophen $N, N^{\prime}$-bis (salycilidene)-1,2-phenylenediamine

absorption spectrometry used for the determination of copper ions is summarized in Table 7. The developed method has a high efficiency factor, a low limit of detection (LOD), and a consumptive index (with some exceptions). Therefore, the developed method is comparable with or even better than those reported by the other researchers and its performance in the determination of $\mathrm{Cu}(\mathrm{II})$ ions in the water and food samples was excellent.

\section{Abbreviations}

Cl: Consumptive index; DLLME: Dispersive liquid-liquid microextraction; EF: Enrichment factor; FAAS: Fame atomic absorption spectrometry; GC: Gas chromatography; GFAAS: Graphite furnace atomic absorption spectrometry; HPLC: High-performance liquid chromatography; ICP-OES: Inductively coupled plasma-optical emission spectrometry; LOD: Limit of detection

\section{Acknowledgments}

The authors are thankful to the Shahrood University of Technology Research Council for the support of this work.

\section{Funding}

This work has been financially supported by the Shahrood University of Technology.

\section{Availability of data and materials}

The data used in this study is presented in the main paper.

\section{Authors' contributions}

HSE and MA synthesized the salophen and SHE performed all of the tests. MA participated in writing a part of the manuscript. GB and MAC contributed to the data analysis and coordinated the work. GB and MA contributed to the manuscript preparation. All authors read and approved the final manuscript.

\section{Competing interests}

The authors declare that they have no competing interests.

\section{Publisher's Note}

Springer Nature remains neutral with regard to jurisdictional claims in published maps and institutional affiliations.
Received: 1 August 2018 Accepted: 2 January 2019

Published online: 14 January 2019

\section{References}

Bader N, Benkhayal AA. Co-precipitation as a sample preparation technique for trace element analysis: an overview. Int J Chem Sci. 2014;12:519-25. http:// www.tsijournals.com/abstract/coprecipitation-as-a-sample-preparationtechnique-for-trace-element-analysis-an-overview-10554.html

Bahadir Z, Bulut VN, Mermer A, Demirbaş N, Duran C, Soylak M, (2018) The separation-preconcentration and determination of ultra-trace gold in water and solid samples by dispersive liquid-liquid microextraction using 4-ethyl1(2-(4-(4-nitrophenyl) piperazin-1-yl) acetyl)thiosemicarbazide) as chelating agent and fame atomic absorption spectrometry. J Iran Chem Soc 15:13471354. doi: https://doi.org/10.1007/s13738-018-1333-z

Behbahani M, Bide Y, Salarian M, Niknezhad M, Bagheri S, Bagheri A, Nabid MR. The use of tetragonal star-like polyaniline nanostructures for efficient solid phase extraction and trace detection of $\mathrm{Pb}(\mathrm{II})$ and $\mathrm{Cu}(\mathrm{II})$ in agricultural products, sea foods, and water samples. Food Chem. 2014;158:14-9. https:// doi.org/10.1016/j.foodchem.2014.02.110.

El-Shahawi M, Al-Saidi H. Dispersive liquid-liquid microextraction for chemical speciation and determination of ultra-trace concentrations of metal ions. TrAC Trends Anal Chem. 2013;44:12-24. https://doi.org/10.1016/j.trac.2012.10.011.

Fan Y, Xu C, Wang R, Hu G, Miao J, Hai K, Lin C. Determination of copper (II) ion in food using an ionic liquids-carbon nanotubes-based ion-selective electrode. J Food Compos Anal. 2017;62:63-8. https://doi.org/10.1016/j.jfca.2017.05.003.

Farajzadeh MA, Bahram M, Mehr BG, Jönsson JA. Optimization of dispersive liquidliquid microextraction of copper (II) by atomic absorption spectrometry as its oxinate chelate: application to determination of copper in different water samples. Talanta. 2008;75:832-40. https://doi.org/10.1016/j.talanta.2007.12.035.

Jalbani N, Soylak M. Ligandless ultrasonic-assisted and ionic liquid-based dispersive liquid-liquid microextraction of copper, nickel and lead in different food samples. Food Chem. 2015;167:433-7. https://doi.org/10.1016/j.foodchem.2014.07.015.

Khalilian F, Rezaee M. Mixed-hemimicelle solid phase extraction followed by dispersive liquid-liquid microextraction of amphetamines from biological samples. J Brazil Chem Soc. 2016;27:2105-13. https://doi.org/10.5935/01035053.20160101.

Khalilian F, Rezaee M. Ultrasound-assisted extraction followed by solid-phase extraction followed by dispersive liquid-liquid microextraction for the sensitive determination of Diazinon and Chlorpyrifos in Rice. Food Anal Method. 2017;10: 885-91. https:/link.springer.com/article/10.1007/s12161-016-0653-9

Khani R, Shemirani F, Majidi B. Combination of dispersive liquid-liquid microextraction and flame atomic absorption spectrometry for 
preconcentration and determination of copper in water samples. Desalination. 2011;266:238-43. https://doi.org/10.1016/j.desal.2010.08.032.

Lemos AV, Santos SM, dos Santos SMJ, Vieira RD, Novaes GC. Determination of copper in water samples by atomic absorption spectrometry after cloud point extraction. Microchim Acta. 2007;157:215-22. https://doi.org/10.1007/ s00604-006-0652-4.

Ming-Jie L, Zhang H-Y, Xiao-Zhe L, Chun-Yan C, Zhi-Hong S. Progress of extraction solvent dispersion strategies for dispersive liquid-liquid microextraction. Chinese J Anal Chem. 2015;43:1231-40. https://doi.org/10.11895/j.issn.0253-3820.150357.

Mirkhani V, Moghadam M, Tangestaninejad S, Bahramian B, MallekpoorShalamzari A. Host (nanocavity of zeolite-Y)-guest (manganese (III) salophen complex) nanocomposite materials: an efficient catalyst for biomimetic alkene epoxidation and alkane hydroxylation with sodium periodate. Appl Catal A Gen. 2007;321:49-57. https://doi.org/10.1016/j.apcata.2007.01.032.

Mohammadi SZ, Afzali D, Baghelani YM. Ligandless-dispersive liquid-liquid microextraction of trace amount of copper ions. Anal Chim Acta. 2009;653: 173-7. https://doi.org/10.1016/j.aca.2009.09.010.

Naseri MT, Hosseini MRM, Assadi Y, Kiani A. Rapid determination of lead in water samples by dispersive liquid-liquid microextraction coupled with electrothermal atomic absorption spectrometry. Talanta. 2008;75:56-62. https://doi.org/10.1016/j.talanta.2007.10.029.

Nishihama S, Hirai T, Komasawa I. Review of advanced liquid-liquid extraction systems for the separation of metal ions by a combination of conversion of the metal species with chemical reaction. Ind Eng Chem Res. 2001;40:308591. https://pubs.acs.org/doi/abs/10.1021/ie010022+.

Özzeybek G, Erarpat S, Chormey DS, Fırat M, Büyükpınar Ç, Turak F, Bakırdere S. Sensitive determination of copper in water samples using dispersive liquid-liquid microextraction-slotted quartz tube-flame atomic absorption spectrometry. Microchem J. 2017;132:406-10. https://doi.org/10.1016/j.microc.2017.02.031.

Pouyan M, Bagherian G, Goudarzi N. Determination of ultra-trace palladium(II) in water, soil and food samples by dispersive liquid liquid microextractionatomic absorbtion spectrometry using 2-mercaptobenzimidazole as complexing agent. Microchem J. 2016;127:46-51. https://doi.org/10.1016/j. microc.2016.02.003.

Quigley A, Cummins W, Connolly D. Dispersive liquid-liquid microextraction in the analysis of milk and dairy products: a review. J Chem. 2016;2016:4040165, 12 pages. https://doi.org/10.1155/2016/4040165.

Rajabi M, Asemipour S, Barfi B, Jamali MR, Behzad M. Ultrasound-assisted ionic liquid based dispersive liquid-liquid microextraction and flame atomic absorption spectrometry of cobalt, copper, and zinc in environmental water samples. J Mol Liq. 2014;194:166-71. https://doi.org/10.1016/j.molliq.2014.01.026.

Reclo M, Yilmaz E, Bazel Y, Soylak M. Switchable solvent based liquid phase microextraction of palladium coupled with determination by flame atomic absorption spectrometry. Int J Environ Anal Chem. 2017;97:1315-27. https:// doi.org/10.1080/03067319.2017.1413185.

Rezaee M, Assadi Y, Hosseini MRM, Aghaee E, Ahmadi F, Berijani S. Determination of organic compounds in water using dispersive liquid-liquid microextraction. J Chromatogr A. 2006;1116:1-9. https://doi.org/10.1016/j.chroma.2006.03.007.

Rezaee M, Yamini Y, Faraji M. Evolution of dispersive liquid-liquid microextraction method. J Chromatogr A. 2010;1217:2342-57. https://doi.org/10.1016/j.chroma. 2009. 11. 088.

Şatıroğlu N, Arpa Ç. Cloud point extraction for the determination of trace copper in water samples by flame atomic absorption spectrometry. Microchim Acta. 2008;162:107-12. https://link.springer.com/article/10.1007/s00604-007-0904-y

Silvestre CIC, Santos JL, Lima JL, Zagatto EA. Liquid-liquid extraction in flow analysis: a critical review. Anal Chim Acta. 2009;652:54-65. https://doi.org/10. 1016/j.aca.2009.05.042.

Xu H, Zhang W, Zhang X, Wang J, Wang J. Simultaneous preconcentration of cobalt, nickel and copper in water samples by cloud point extraction method and their determination by flame atomic absorption spectrometry. Procedia Environ Sci. 2013;18:258-63. https://doi.org/10.1016/j.proenv.2013.04.033.

Yilmaz E, Soylak M. Development a novel supramolecular solvent microextraction procedure for copper in environmental samples and its determination by microsampling flame atomic absorption spectrometry. Talanta. 2014;126:1915. https://doi.org/10.1016/j.talanta.2014.03.053

Yilmaz E, Soylak M. Switchable solvent based liquid phase microextraction of copper(II): optimization and application to environmental samples. J Anal At Spectrom. 2015;30:1629-35. https://doi.org/10.1039/C5JA00012B.

Yilmaz E, Soylak M. Latest trends, green aspects, and innovations in liquid-phasebased microextraction techniques: a review. Turk J Chem. 2016:40:868-93. https://doi.org/10.3906/kim-1605-26. http://journals.tubitak.gov.tr/chem/
Yin Q, Zhu Y, Ju S, Liao W, Yang Y. Rapid determination of copper and lead in Panax notoginseng by magnetic solid-phase extraction and flame atomic absorption spectrometry. Res Chem Intermediat. 2016;42:4985-98. https://doi. org/10.1007/s11164-015-2340-7.

Zeeb M, Ganjali MR, Norouzi P, Kalaee MR. Separation and preconcentration system based on microextraction with ionic liquid for determination of copper in water and food samples by stopped-flow injection spectrofluorimetry. Food Chem Toxicol. 2011;49:1086-91. https://doi.org/10. 1016/j.fct.2011.01.017.

Zhong WS, Ren T, Zhao L. Determination of Pb (Lead), Cd (Cadmium), Cr (Chromium), Cu (Copper), and Ni (Nickel) in Chinese tea with high-resolution continuum source graphite furnace atomic absorption spectrometry. J Food Drug Anal. 2016;24:46-55. https://doi.org/10.1016/j.jfda.2015.04.010.

\section{Submit your manuscript to a SpringerOpen ${ }^{\circ}$ journal and benefit from:}

- Convenient online submission

- Rigorous peer review

- Open access: articles freely available online

- High visibility within the field

- Retaining the copyright to your article

Submit your next manuscript at $\boldsymbol{\nabla}$ springeropen.com 